\title{
CFD simulation of forced heat transfer of gas in pipe
}

\author{
Zhivko Kolev ${ }^{1}$ and Seher Kadirova ${ }^{2}$ \\ ${ }^{1}$ University of Ruse, Department of Thermotechnics, Hydraulics and Engineering Ecology, 7017 \\ Ruse, Bulgaria \\ ${ }^{2}$ University of Ruse, Department of Electronics, 7017 Ruse, Bulgaria
}

\begin{abstract}
This paper presents results from CFD simulation of heat transfer processes in ABAQUS. The investigations are realized at forced convection of air in steel pipe. Verification of the computing mesh and validation of the model, have been done. The average heat convection coefficients have been determined by methodology based on criteria equations, and on simulation methodology. Heat transfer processes between air flow in a steel pipe and the environment, have been experimentally accomplished. In order to analyze the processes of heat convection between the fluid and the internal surface of the pipe, numerical modelling is applied. A geometric model of the fluid flowing in the pipe is built. The computing mesh has been verified by increasing the number of cells and nodes. The numerical model has been validated based on experimentally measured temperature values and the simulation data. The heat convection coefficients have been investigated by analogy of the above. The results demonstrate that the numerical model is adequate and can be used to study similar heat transfer processes.
\end{abstract}

\section{Introduction}

Processes of heat transfer at forced convection are realized in heat exchange apparatuses [13]. Many experimental and numerical methods have been proposed for obtaining the parameters of heat transfer processes and characteristics of the fluid flow [1-7].

The correct defining of boundary conditions is obligatory for solving of numerical heat transfer problems [8].

Generally, in numerical simulation the used equations are discretized by cells from the division of computational domain using finite element method [3, 7, 10]. Three dimensional discrete model are being created in ABAQUS FEA engineering software in order to analyze the phenomena occurring the heat transfer process [11-13]. One of the turbulence model, which can be used for simulation of fluid flow is "Spalart-Almaras".

More accurate estimation of the heat transfer coefficient is required for the high performance heat exchanger equipment [4]. Determination of heat convection coefficient can be done in different ways [2]. The aim of the paper is determination of the heat convection coefficient between the air flow and the pipe's internal surface, by methodology based on criteria equations, as well as simulation, based on ABAQUS. 


\section{Methodology}

\subsection{Schematic diagram of the simulation model}

Schematic diagram of the simulation model is presented in Figure 1. The object of investigation presented in the figure is the fluid flowing in the pipe. The input parameters for CFD simulation are: bulk fluid temperatures in the pipe's inlet and outlet ( $T_{f, 1}$ and $T_{f, 2}$, $\left.{ }^{\circ} \mathrm{C}\right)$; average fluid velocity in the pipe's inlet $\left(U_{\text {input }}, \mathrm{m} / \mathrm{s}\right)$; manometric fluid pressure in the pipe's outlet $\left(p_{m, \text { output }}, \mathrm{Pa}\right)$; heat flux between the fluid and the pipe's internal surface $(q$, $\left.\mathrm{W} / \mathrm{m}^{2}\right)$; pipe's internal diameter $(d, \mathrm{~m})$; pipe's length $(l, \mathrm{~m})$. The values of the above parameters have been experimentally determined.

The selection of the boundary conditions for implementation of CFD simulations is determined by the necessity to obtain the temperature distribution in the fluid on the base of the average heat flux $q$. The heat flux has been calculated through the following parameters: mass flow rate; average mass specific heat capacity at constant pressure; temperature difference " $T_{f, 1}-T_{f, 2}$ "; internal tube diameter $d$ and pipe length $l$. Therefore, this requires setting of the heat flux q, the inlet bulk temperature $T_{f, 1}$, and the outlet bulk temperature $T_{f, 2}$ as boundary conditions.

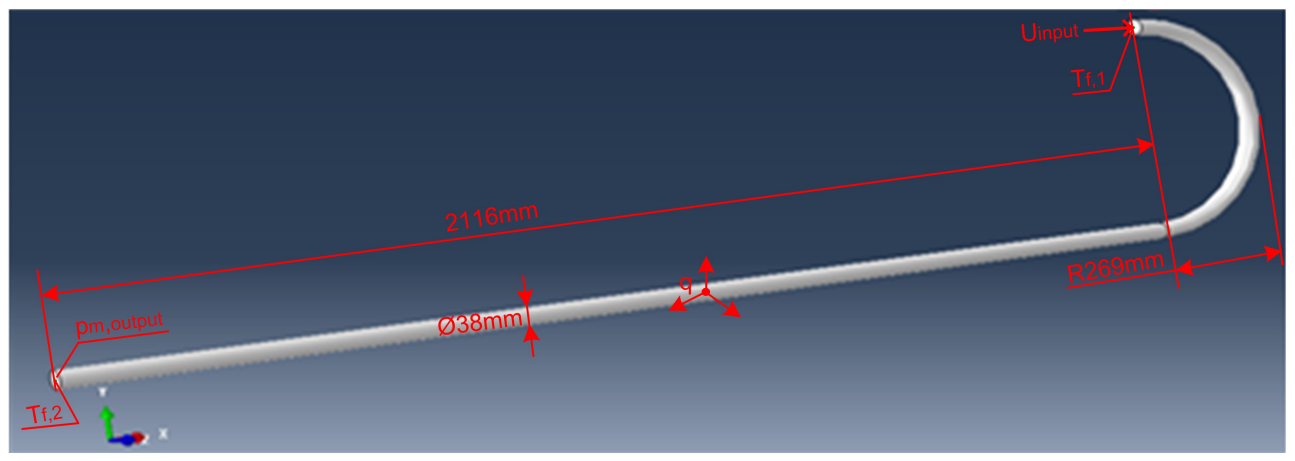

Fig. 1. Schematic diagram of the simulation model.

\subsection{Verification of computing mesh and validation of CFD model}

In Figure 2 is presented the scheme for verification of computing mesh and validation of CFD model. They are implemented based on pipe's internal temperatures, taken in the corresponding cross-sections.

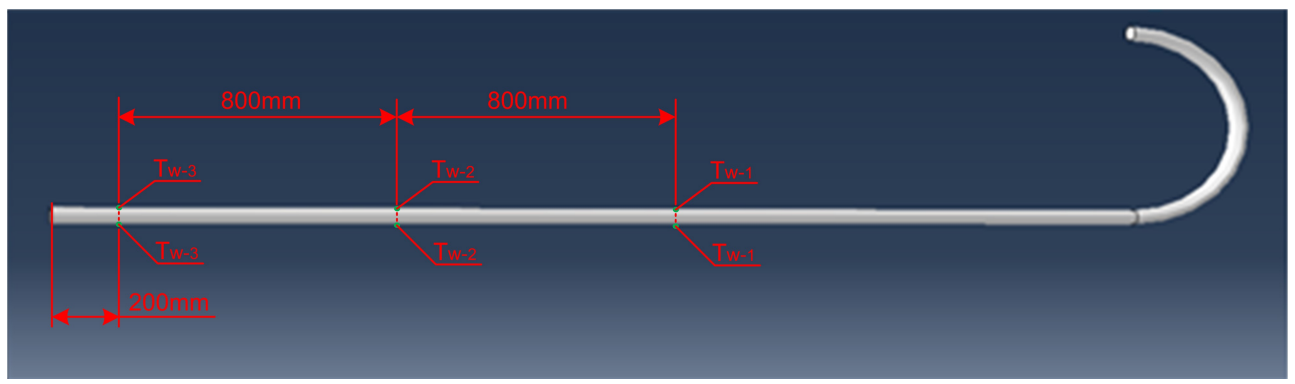

Fig. 2. Scheme of the cross-sections for verification and validation. 
The parameter for verification of the computing mesh is the average simulation value of the temperature $T_{w-3}$. Based on verification results, the computing mesh for simulation of the studied heat transfer processes is being chosen.

The validation of CFD model is performed by comparing simulation and experimental values of $T_{w-1}, T_{w-2}$ and $T_{w-3}$, using the selected computing mesh.

\subsection{Calculation of the heat convection coefficient}

The average heat convection coefficient $\left(h_{c}, \mathrm{~W} / \mathrm{m}^{2}\right)$ between the fluid and the pipe's internal surface is calculated in two methods - based on criteria equations, and based on simulation data. According to the first method the following criteria equation has been used:

$$
N u_{f d}=0.018 \cdot \operatorname{Re}_{f d}^{0.8} \cdot \varepsilon_{l}
$$

The number of Reynolds $R e_{f d}$ is calculated on the basis of experimentally determined fluid temperatures $\left(T_{f, 1}\right.$ and $\left.T_{f, 2}\right)$, and fluid velocity in the inlet pipe's cross-section $\left(U_{\text {input }}\right)$. The coefficient $\varepsilon_{l}$ is determined on the basis of the ratio $l / d$.

The calculation of the heat convection coefficient with simulation data is by the equation [2]:

$$
h_{c}=q / \Delta T
$$

where $\Delta T$ is the cross-section temperature difference, calculated as an average value of the temperature differences in six fluid cross-sections, K (Figure 3).

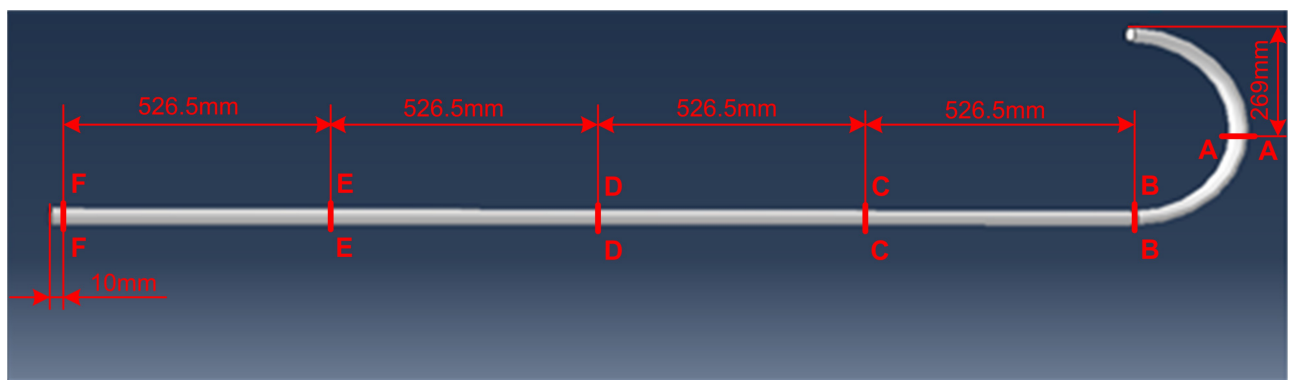

Fig. 3. Scheme of the cross-sections for calculation of the temperature difference $\Delta T, \mathrm{~K}$.

\section{Results and discussion}

\subsection{Input parameters of the simulated heat transfer processes}

For applying of the numerical model for different cases, and for calculating the heat convection coefficient according to the above mentioned methods, three heat transfer processes have been realized and investigated via fluid flow rate regulation.

Table 1 presents the values of the input parameters for CFD simulation of the investigated heat transfer processes. 
Table 1. Input parameters for simulation of the heat transfer processes.

\begin{tabular}{|c|c|c|c|c|c|}
\hline $\begin{array}{c}\text { Heat } \\
\text { transfer } \\
\text { processes }\end{array}$ & $\mathbf{T}_{\mathbf{f}, \mathbf{1}}{ }^{\mathbf{0}} \mathbf{C}$ & $\mathbf{T}_{\mathbf{f}, \mathbf{2}},{ }^{\mathbf{o}} \mathbf{C}$ & $\mathbf{U}_{\text {input }}, \mathbf{m} / \mathbf{s}$ & $\mathbf{p}_{\mathbf{m}, \mathbf{o u t p u t}}, \mathbf{P a}$ & $\mathbf{q}, \mathbf{W} / \mathbf{m}^{\mathbf{2}}$ \\
\hline Process I & 131 & 101 & 44.63 & 0 & 3873.52 \\
\hline Process II & 137 & 102 & 41.88 & 0 & 4176.30 \\
\hline Process III & 141 & 106 & 36.16 & 0 & 3734.36 \\
\hline
\end{tabular}

The pipe's internal diameter is $d=0.038 \mathrm{~m}$, and length is $l=2.901 \mathrm{~m}$. They are calculated on the base of the schematic diagram of the simulation model, presented in Figure 1.

\subsection{Results from verification of the computing mesh, and validation of CFD model}

Verification and validation have been realized for Process I (Table 1).

$>$ Results, obtained from verification of the computing mesh

Table 2 presents the parameters of the investigated variants of computing mesh and the determined simulation value of the temperature $T_{w-3}$, used for verification.

Figure 4 presents the fluid cross-sections for determination of $T_{w-3}$. This temperature is calculated as the average temperature value for computing nodes, located on the external cylindrical surface of the fluid, which in fact is the internal heat exchange surface of the pipe. The figure presents information about the typical shape and the number of the computing cells as well as the number of the computing nodes for the investigated variants of mesh. The set shape of the computing cells is "Tet" (a 4-node linear fluid tetrahedron).

Table 2. Parameters of the computing meshes and the calculated simulation value of $T_{w-3}$.

\begin{tabular}{|c|c|c|c|c|}
\hline $\begin{array}{c}\text { Variants of } \\
\text { computing mesh }\end{array}$ & $\begin{array}{c}\text { Shape of the } \\
\text { computing cells }\end{array}$ & $\begin{array}{c}\text { Approximate } \\
\text { size of the } \\
\text { computing cells, } \\
\mathbf{m}\end{array}$ & $\begin{array}{c}\text { Number of the } \\
\text { computing cells }\end{array}$ & $\begin{array}{c}\mathbf{T}_{\mathbf{w}-3} \text { (simulated), } \\
{ }^{\mathbf{0}} \mathbf{C}\end{array}$ \\
\hline Mesh I & Tet & 0.0100 & 21733 & 68.28 \\
\hline Mesh II & Tet & 0.0050 & 151141 & 73.14 \\
\hline Mesh III & Tet & 0.0045 & 209028 & 73.87 \\
\hline Mesh IV & Tet & 0.0040 & 276137 & 74.19 \\
\hline
\end{tabular}




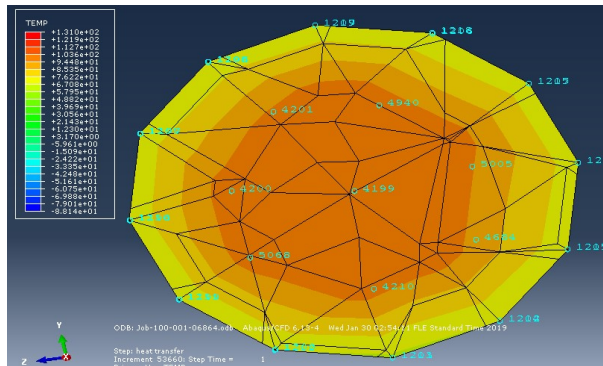

a) Mesh I

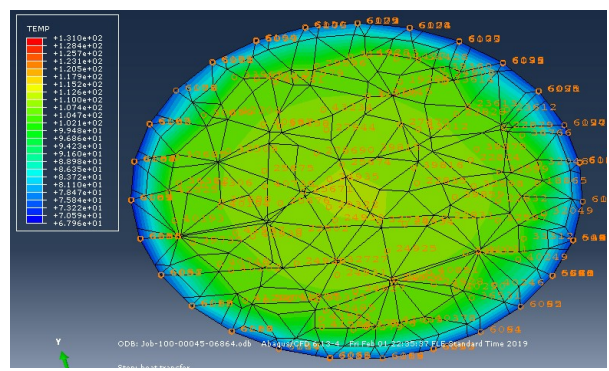

c) Mesh III

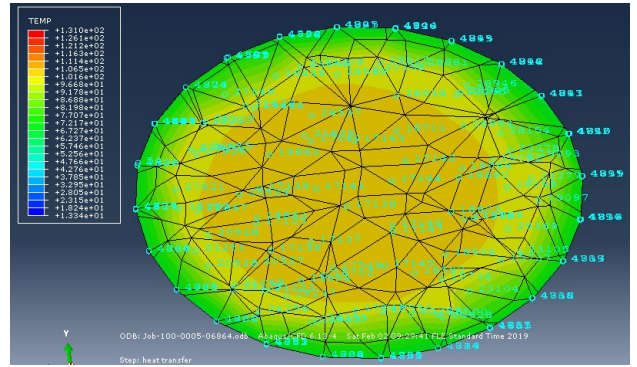

b) Mesh II

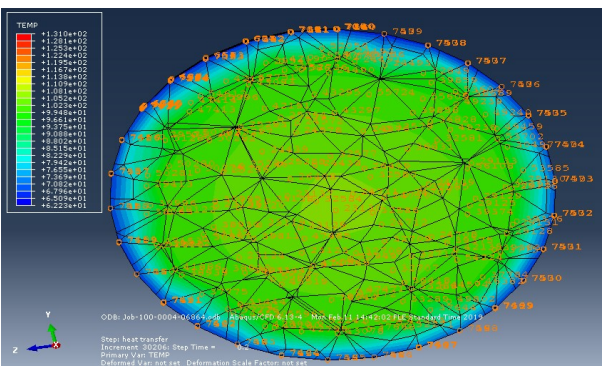

d) Mesh IV

Fig. 4. Fluid cross-section for determination of the simulation value of $T_{w-3}$ at different computing mesh variants.

It was found that the difference in the values of $T_{w-3}$ between the contiguous variants III and IV is relatively small $\left(0.32^{\circ} \mathrm{C}\right)$. It can be assumed that from the point of view of the model's accuracy, the further increase the mesh density is not required. Therefore, the variant Mesh IV is selected.

$>$ Results from validation of CDF model

Table 3 presents results from validation of the numerical model, accomplished by comparison of experimental and simulation values of the temperatures $T_{w-1}, T_{w-2}$ and $T_{w-3}$. The CFD model's error has been calculated (Table 3).

Table 3. Results from model's validation, and errors.

\begin{tabular}{|c|c|c|c|}
\hline Temperature & $\begin{array}{c}\text { Experimental } \\
\text { value, }{ }^{\mathbf{0}} \mathbf{C}\end{array}$ & $\begin{array}{c}\text { Simulation value, } \\
{ }^{\mathbf{0}} \mathbf{C}\end{array}$ & Model's error, $\pm \mathbf{\%}$ \\
\hline $\mathrm{T}_{\mathrm{w}-1}$ & 86.00 & 87.57 & +1.79 \\
\hline $\mathrm{T}_{\mathrm{w}-2}$ & 79.00 & 76.52 & -3.14 \\
\hline $\mathrm{T}_{\mathrm{w}-3}$ & 74.00 & 74.19 & +0.26 \\
\hline
\end{tabular}

From the results presented in Table 3, can be concluded that the highest calculated model's error of $-3.14 \%$ is less than the generally accepted maximum permissible engineering error of $\pm 5 \%$.

\subsection{Results for calculated heat convection coefficient and simulation obtained temperature field}


Table 4. Results for heat convection coefficient

\begin{tabular}{|c|c|c|c|}
\hline $\begin{array}{c}\text { Investigated heat } \\
\text { transfer process }\end{array}$ & $\begin{array}{c}\mathbf{h}_{\mathbf{c}} \text { (by criteria } \\
\text { equations), } \\
\mathbf{W} /\left(\mathbf{m}^{\mathbf{2}} \mathbf{K}\right)\end{array}$ & $\begin{array}{c}\mathbf{h}_{\mathbf{c}} \text { (by simulation } \\
\mathbf{m e t h o d}^{\prime} \mathbf{W} /\left(\mathbf{m}^{\mathbf{2}} . \mathbf{K}\right)\end{array}$ & Difference, \% \\
\hline Process I & 111.66 & 115.56 & -3.49 \\
\hline Process II & 110.53 & 110.08 & +0.41 \\
\hline Process III & 94.71 & 98.04 & -3.52 \\
\hline
\end{tabular}

Table 4 presents results for heat convection coefficient $h_{c}$, respectively calculated values on the base on criteria equations and values observed by simulation method. The percentage difference has also been calculated and analyzed.

Figure 5 presents the simulated temperature field in the longitudinal cross-section of the fluid, which gives information about the temperature values, used for calculation of $\Delta T, \mathrm{~K}$.

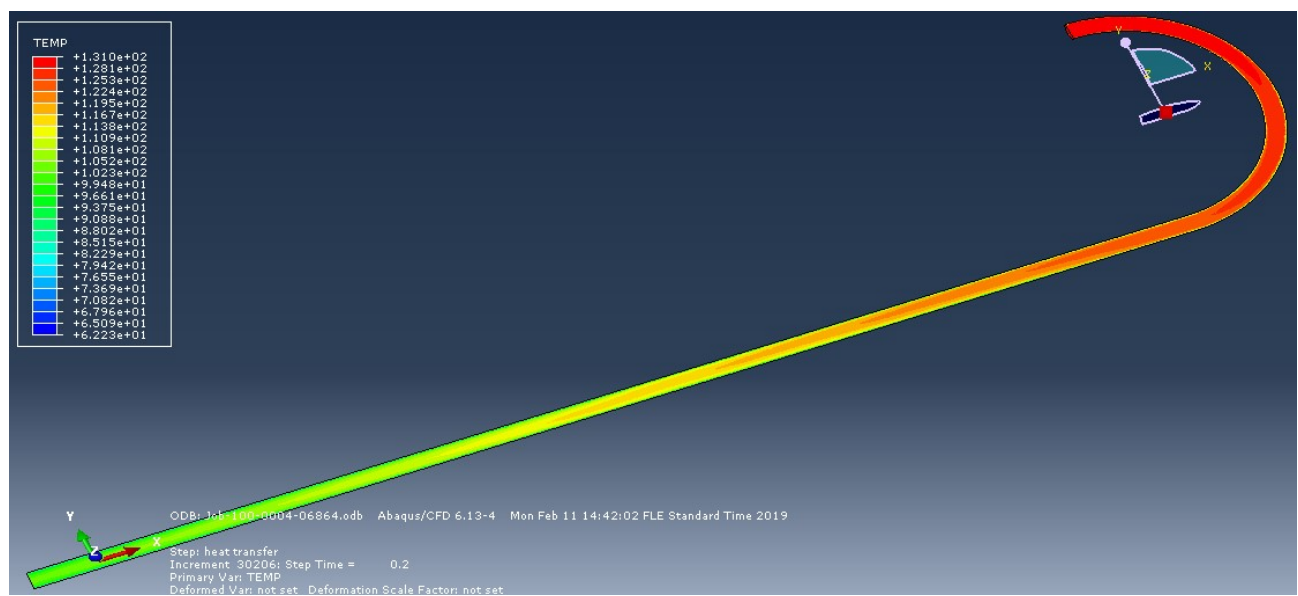

a) Process I

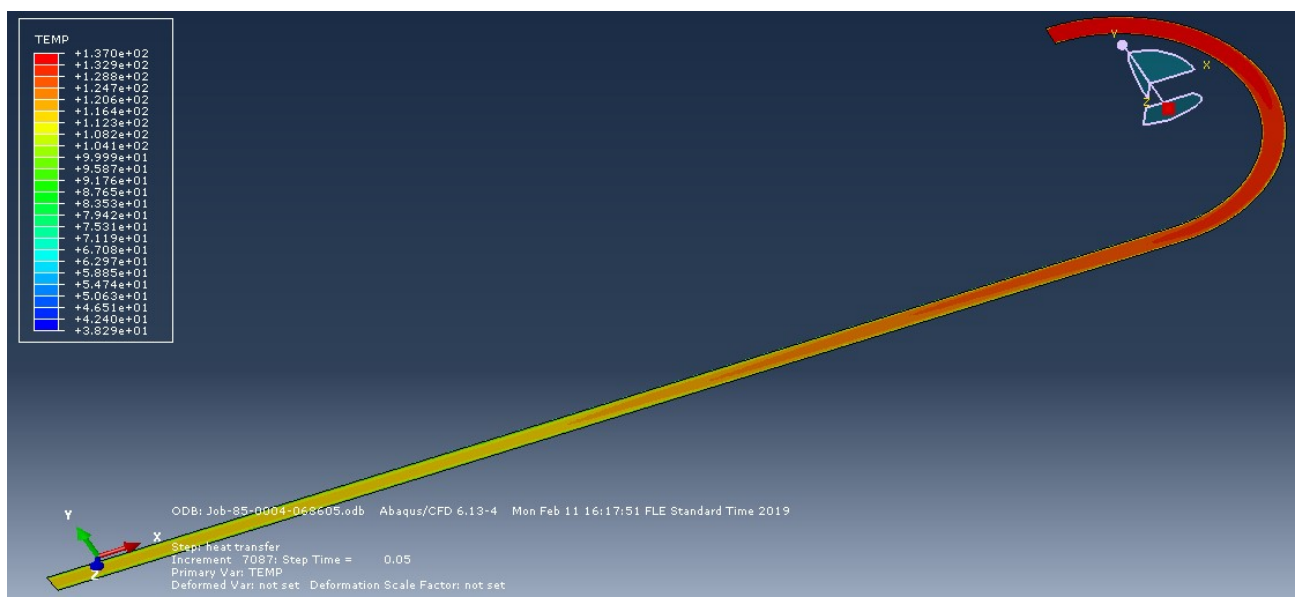

b) Process II 


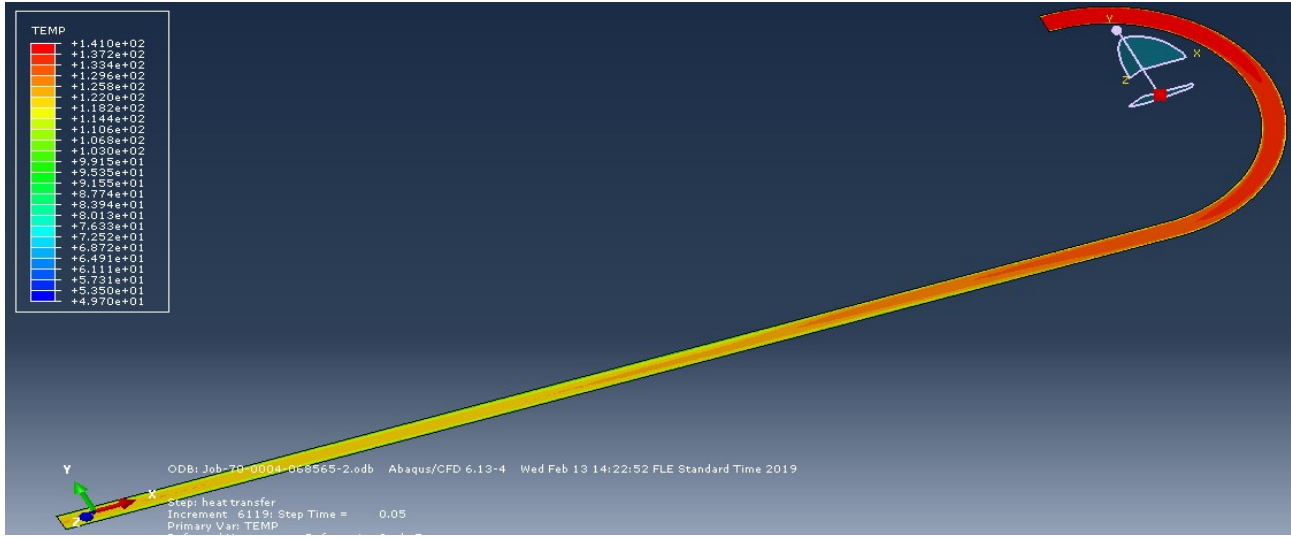

c) Process III

Fig. 5. Simulation results for temperature field in the longitudinal cross-section of the fluid.

Figure 6 presents information about the temperature distribution and the fluid velocity distribution in cross-section "D-D".

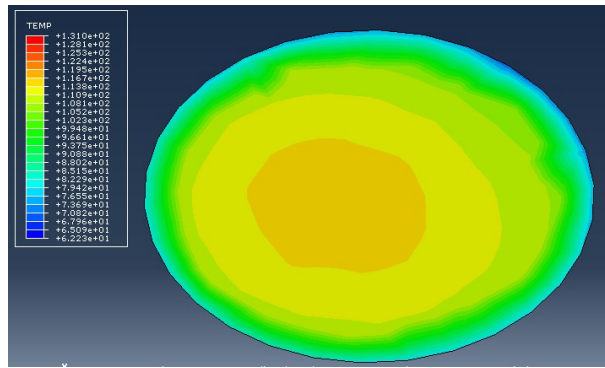

Temperature distribution - Process I

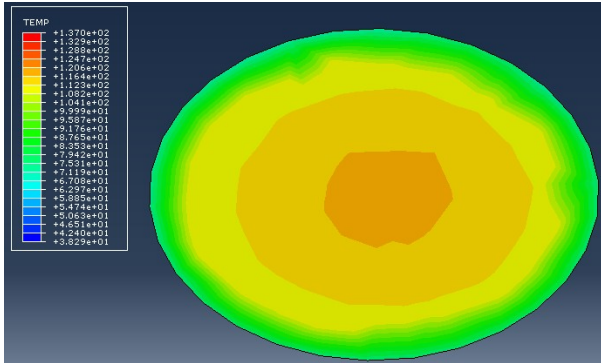

Temperature distribution - Process II

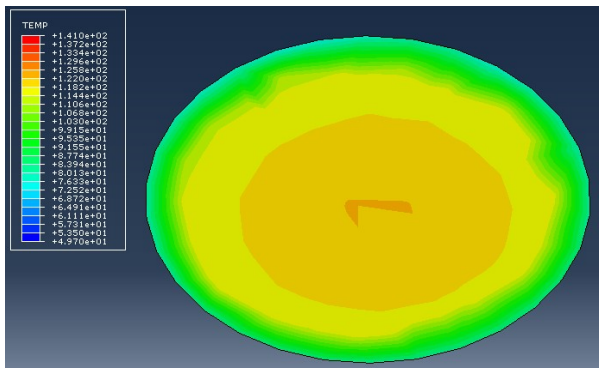

Temperature distribution - Process III

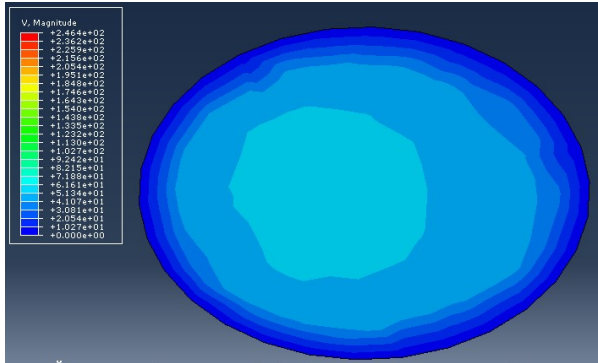

Velocity distribution - Process I

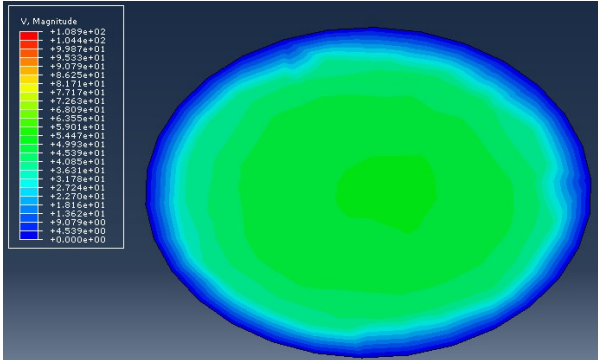

Velocity distribution - Process II

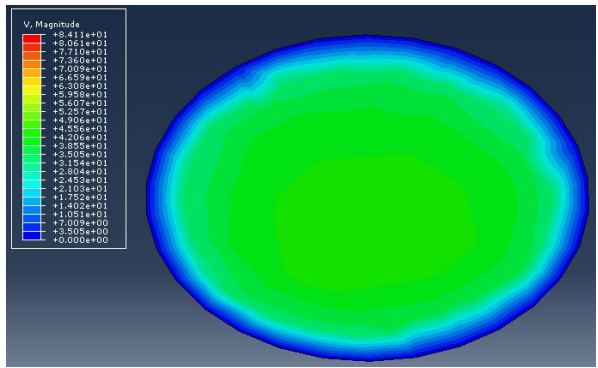

Velocity distribution - Process III

Fig. 6. Simulation results for the temperature distribution and the fluid velocity distribution in crosssection "D-D". 
The results observed from numerical simulation covers the results calculated by criteria equations. The highest calculated percentage difference of $-3.49 \%$ is less than $\pm 5 \%$. Therefore, it can be concluded that the proposed scheme for determination of $\Delta T$ is appropriate for simulation studies.

\section{Conclusion}

A methodology for investigation of heat transfer processes at forced convection of air in steel pipe by numerical simulation in ABAQUS has been proposed.

A scheme of fluid cross-sections for verification of the computing mesh and validation of CFD model has been developed.

A method for calculation of the average heat convection coefficient, via determination of simulation temperatures in the fluid cross-sections has been developed and proved.

From the results of the computing mesh verification can be concluded that with increase of the mesh density, the difference between the temperature values (used as a basis for verification) has been reduced.

From the results obtained for the validation of CFD model is seen that the maximum value of the model's error is less than the maximum permissible technical error. Therefore, the CFD model is adequate and can be used for simulation of similar heat transfer processes.

The results obtained for the heat convection coefficient indicate that the proposed method provides a sufficiently high accuracy.

\section{References}

1. A.H. Dhumal, G.M. Kerkal, K.T. Pawale, Heat transfer enhancement for tube in tube heat exchanger using twisted tape inserts, IJAERS 4, 89 (2017)

2. K. Majewski, S. Grądziel, CFD Simulations of Heat Transfer in Internally Helically Ribbed Tubes, Chem. Process Eng. J. 37 (2), 251 (2016)

3. C. Oon, H. Togun, S. Kazi, A. Badarudin, M. Zubir, E. Sadeghinezhad, Numerical simulation of heat transfer to separation air flow in an annular pipe, Int. Commun. Heat Mass. J. 39, 1176 (2012)

4. Han-Taw Chen, Yu-Jie Chiu, Chein-Shan Liu, Jiang-Ren Chang, Numerical and experimental study of natural convection heat transfer characteristics for vertical annular finned tube heat exchanger, Int. J. Heat Mass. Tran. 109, 378 (2017)

5. E. Dimofte, F. Popescu, I. Ion, Numerical modelling of mixing fluids at different temperatures, Proceedings of TE-RE-RD, 35 (2016)

6. W. Osley, P. Droegemueller, P. Ellerby, CFD Investigation of Heat Transfer and Flow Patterns in Tube Side Laminar Flow and the Potential for Enhancement, Chem. Eng. Trans. J. 35, 997 (2013)

7. K. Yordanov, T. Mechkarova, A. Stoyanova, P. Zlateva, Determination of the temperature of cathode unit of indirect plasma burner through a computer simulation model, Proceedings of IITI'17, 403 (2018)

8. K. Yordanov, P. Zlateva, I. Hadzhidimov, A. Stoyanova, Testing and clearing the high temperature module error from 0 to $1250{ }^{\circ} \mathrm{C}$ for measurement with $16 \mathrm{~K}$-type thermocouples, Proceedings of SIELA, 480 (2018)

9. S. Elena-Madalina, Gh. Voicu, G. Ipate, A.G. Constantin, Modelling and numerical analysis by the finite element method of wheat milling process in roller mills, Proceedings of TE-RE-RD, 249 (2013) 
10. W. Igo, L. Mihaescu, Turbulent forced convection air flow in a Venturi channel, Proceedings of TE-RE-RD, 51 (2013)

11. Z. Saternus, W. Piekarska, Numerical analysis of thermomechanical phenomena in laser welded pipe-to-flat, Procedia Eng. J. 177, 196 (2017)

12. R. Steinheimer, B. Engel, Thermal influences during rotary draw bending of tubes from stainless steel, Procedia Eng. J. 81, 2165 (2014)

13. K. Abdelkader, K. Youcef, T. Sabiha, Numerical simulation of free vibrations of multilayer composite beams, Proceedings of ICAME, 105 (2016) 